The year 2002 marked the birth of our journal 'Artha' dedicated entirely to social sciences - with this a dream became a reality. Since then never losing sight of the values propounded by our management to bring excellence in every sphere of activity, we have with enthusiasm gone where very few have ventured. Artha thoroughly demonstrates the interdisciplinary nature of social sciences. Our firm belief is that research should not end up only in the annals of academia but be used as a tool to change and improve society.

Several articles on women study focus on the social and structural study of gender as the basic principle of social order and as a primary social category. The authors remind us that gender nor culture is a static form. Rather each shapes the other through history, social relations, and the material basis of social production and reproduction. Studying gender across cultures alerts scholars to the emergent ways in which women and men give meaning to their lives and shape, though under conditions of unequal power, the conditions under which they live.

As globalization becomes the new mantra of the powerful in the planet, it is time to take stock and critically appraise the whole process. The articles try to develop an analytical framework for understanding the changing paradigm of trade in services in the newly emerging global economic environment. There are several articles from the psychological perspective. These articles highlight the role of psychologists in a developing society for an understanding of Indian behaviour and psyche.

Teaching in recent times has been much in the news and educators have been highlighting the necessity to view the whole process in a new light. Cultural critiques of the nation state have failed to take account of material entitlements and intellectual opportunities in the context of persistent deprivation and inequalities of certain sections of society. The volumes include several articles on sustainable development - watershed development, forestry and care development and tribal development.

I would like to express my thanks to Fr. Paulson, editor of the first three volumes, for his outstanding work in establishing this journal. Our principal Fr. Thomas C. Mathew has been generous in his support for 'Artha'. His continuing commitment to academic excellence has helped scholarship to thrive at the college. I also want to express my appreciation to our publication co-ordinator P. Krishnaswami for his skills - both intellectual and administrative. Last but not the least we wish to thank our esteemed readers, contributors, members of the advisory board for helping us in making this publication a unique and successful venture.

\title{
Pritha Dasgupta
}

Executive Editor 